\title{
Feedback of a Non-Truncated Erlang Queuing System with Balking and Retention of Reneged Customers
}

\author{
Kotb Abdel Hamid Kotb, Moamer Akhdar* \\ Department of Mathematics and Statistics, Faculty of Science, Tanta University, Tanta, Egypt \\ Email address: \\ msukss2010@gmail.com (K. A. H. Kotb), msukss2010@yahoo.com (M. Akhdar) \\ ${ }^{*}$ Corresponding author
}

\section{To cite this article:}

Kotb Abdel Hamid Kotb, Moamer Akhdar. Feedback of a Non-Truncated Erlang Queuing System with Balking and Retention of Reneged Customers. Applied and Computational Mathematics. Vol. 7, No. 2, 2018, pp. 40-49. doi: 10.11648/j.acm.20180702.12

Received: January 17, 2018; Accepted: January 31, 2018; Published: February 27, 2018

\begin{abstract}
The aim of this paper is to derive the analytical solution of the non-truncated single-channel Erlangian queue: $\mathrm{M} / \mathrm{E}_{\mathrm{k}} / 1$ at the steady-state with adding the concepts of balking, feedback strategy and retention of reneged customers. We obtain the probabilities that there are $\mathrm{n}$ customers in the system and the customers in the service occupces stage $s,(s=1,2, \ldots$, $k$ ), the probability of empty system and some measures of effecting of queuing system are obtained using the iterative method. Some important queueing models are derived as special cases of this system. Some numerical values are given showily the effect of correlation between the probabilities and the additional concepts.
\end{abstract}

Keywords: Balking, Non-Truncated, Feedback, Queueing System, Iterative Method, Retention of Reneged Customers

\section{Introduction}

Has been studying the queue in which the service time Erlangian has recently been a good study. White et al. [1] studied non-truncated queue: $\mathrm{M} / \mathrm{E}_{\mathrm{j}} / 1$ who obtained the solution from of generating function and the probabilities could be obtained by power series expansion. Kotb [2] derived an analytical solution of the state-dependent Erlangian queue: $\mathrm{M} / \mathrm{E}_{\mathrm{j}} / 1 / \mathrm{N}$ with balking. In 2005 Shawky [3] study the service Erlangian machine interference model: $\mathrm{M} / \mathrm{E}_{\mathrm{r}} / 1 / \mathrm{k} / \mathrm{N}$ with balking and reneging. On a truncated Erlangian queueing system with state - dependent service rate, balking and reneging is obtained by Paoumy [7] using iterative method. Also, Madhu and Kumar [4] developed a $\mathrm{M} / \mathrm{E}_{\mathrm{k}} / 1$ queueing system with working vacation. Other related studies are presented by Abid and Al - Madi [8], Kotb and Moamer [12], Mishra and Dinesh [6], Jayachitra and James Albert [10] and [11] and Jayachitra et al. [9]. Recently, Jeganathan et al. [13] Focused on $\mathrm{M} / \mathrm{E}_{\mathrm{K}} / 1 / \mathrm{N}$ queueing system with some important concepts.

In this article, we have proposed derive the analytical solution of the non-truncated single-channel Erlangian queue: $\mathrm{M} / \mathrm{E}_{\mathrm{k}} / 1$ at the steady-state with adding the concepts of balking, feedback strategy and retention of reneged customers. The express probabilities that there are $n$ customers in the system and the customer in the service occupies $\mathrm{s}$ stage, the probability of empty system are obtained using a recurrence relation. Some special cases are deduced, some measures of effectiveness. Finally, a simulation study has been considered to illustrate the numerical application for the model.

\section{Basic Notations and Assumptions}

To construct the system of this paper, we define the following parameters:

$p_{n s}=$ Stead-state probability that there are $\mathrm{n}$ customers in the system and the customer in service being in phase $s$ $(1 \leq s \leq k)$, in which the phases are numbered backward.

$p_{0}=$ Stead-state probability that there are no customers in the system.

$k=$ The first phase of service.

$s=$ The service phases.

$\lambda=$ Mean arrival rate.

$\mu=$ Mean service rate per service representative.

$q=$ Probability that a customer joins the departure 
process.

$1-q=$ Probability that a customer joins the end of the original queue.

$p=$ Probability that a customer may leave the queue.

$1-p=$ Probability that a customer may remain in the queue for service.

$\alpha=$ Reneging rate of a certain length of time which a customer will wait for service.

$\mathrm{n}=$ Number of customers in the system.

$\rho=\lambda / \mu=$ Utilization factor.

$L=$ Expected number of customers in the system.

$L_{q}=$ Expected number of customers waiting to be served.

The assumptions of this model are listed as follows:

(1) Customers arrive at the server one by one according to Poisson process with rate $\lambda_{n}$. Assume $(1-\beta)$ be the probability that a customer balks, $0 \leq \beta<1, n \geq 1$; and $\beta=1, n=0$. Thus it is clear that:

$$
\lambda_{n}=\left\{\begin{array}{l}
\lambda, n=0 \\
\beta \lambda, n \geq 1
\end{array}\right.
$$

$$
\begin{aligned}
& \lambda p_{0}-q k \mu p_{11} \quad=0, \quad n=0 \\
& (q k \mu+\beta \lambda) p_{1 s}-q k \mu p_{1, s+1} \\
& (q k \mu+\beta \lambda) p_{1 k}-\lambda p_{0}-(q k \mu+\alpha p) p_{21} \\
& \left.\begin{array}{cr}
=0, & 1 \leq s \leq k-1 \\
=0, & s=k
\end{array}\right\}, n=1 \\
& {[q k \mu+(n-1) \alpha p+\beta \lambda] p_{n, s}-\beta \lambda p_{n-1, s}} \\
& -[q k \mu+(n-1) \alpha p] p_{n, s+1} \\
& {[q k \mu+(n-1) \alpha p+\beta \lambda] p_{n, k}-\beta \lambda p_{n-1, k}} \\
& -[q k \mu+n \alpha p] p_{n+1,1} \\
& \left.\begin{array}{c}
=0, \quad 1 \leq s \leq k-1 \\
=0, \quad s=k
\end{array}\right\}, n \geq 2
\end{aligned}
$$

$$
p_{1 k}=\xi_{1}^{k-1} u_{1} p_{0}, \quad s=k
$$

use the iterative method as follows:

Solving equation (1), we get:

$$
p_{11}=\omega_{0} p_{0}, u_{1}=\omega_{0}
$$

with

$\omega_{n}=\left\{\begin{array}{l}\frac{\lambda}{q k \mu}, n=0 \\ \frac{\beta \lambda}{q k \mu}, n \geq 1\end{array}\right.$ and $\xi_{n}=\varphi_{n}+\frac{\beta \lambda}{q k \mu} ; \varphi_{n}=1+\frac{(n-1) \alpha p}{q k \mu}$

From the first equation of (2) and equation (5), we obtain:

$$
p_{1 s}=\xi_{1}^{s-1} p_{11}
$$

Substituting equation (4) into (6), one can easily get:

$$
p_{1 s}=\xi_{1}^{s-1} u_{1} p_{0}, \quad 1 \leq s \leq k-1,
$$

From the second equation of (2) and equation (5), we get:

$$
p_{21}=\frac{1}{\varphi_{2}}\left(\xi_{1}^{k} p_{11}-u_{1} p_{0}\right)
$$

Substituting equation (4) into (6), we obtain:

$$
p_{21}=\frac{u_{2}}{\varphi_{2}} p_{0}
$$

with

$$
u_{2}=u_{1}\left(\xi_{1}^{k}-1\right)
$$

Using the first equation of (3) with $n=2$ and equation (5), we find: 


$$
p_{2 s}=\left(\frac{\xi_{2}}{\varphi_{2}}\right)^{s-1} p_{21}+\frac{\omega_{2}}{\varphi_{2}}\left(\frac{\xi_{2}}{\varphi_{2}}\right)^{-1} p_{1 s}, \quad 1 \leq s \leq k-1
$$

Substituting equations (7) and (10) into (12), one gets:

$$
p_{2 s}=\frac{1}{\varphi_{2}}\left[\left(\frac{\xi_{2}}{\varphi_{2}}\right)^{s-1} u_{2}+u_{1} \omega_{2}\left(\frac{\xi_{2}}{\varphi_{2}}\right)^{-1} \xi_{1}^{s-1}\right] p_{0}, \quad 1 \leq s \leq k-1
$$

Let $s=1,2,3, \ldots,(k-1)$ in equation (13) it can be deduced by recursive manipulation that:

$$
p_{2 s}=\frac{1}{\varphi_{2}}\left[\left(\frac{\xi_{2}}{\varphi_{2}}\right)^{s-1} u_{2}-u_{1} \omega_{2} \sum_{\tau_{1=1}}^{s-1}\left(\frac{\xi_{2}}{\varphi_{2}}\right)^{s-\tau_{1}-1} \xi_{1}^{\tau_{1}-1}\right] p_{0}, 1 \leq s \leq k
$$

As before, from the second equation of (3) at $n=2$ and equation (5), we get:

$$
p_{31}=\frac{1}{\varphi_{3}}\left(\xi_{2} p_{2 k}-\omega_{2} p_{1 k}\right)
$$

Substituting equations (8) and (14) into (15), one gets:

$$
p_{31}=\frac{u_{3}}{\varphi_{3}} p_{0}
$$

with

$$
u_{3}=\left(\frac{\xi_{2}}{\varphi_{2}}\right)^{k} u_{2}-u_{1} \omega_{2} \sum_{\tau_{1}=1}^{k}\left(\frac{\xi_{2}}{\varphi_{2}}\right)^{k-\tau_{1}} \xi_{1}^{\tau_{1}-1}
$$

Also, from the first equation of (3) with $n=3$ and equation (5), we obtain:

$$
p_{3 s}=\left(\frac{\xi_{3}}{\varphi_{3}}\right)^{s-1} p_{31}+\frac{\omega 3}{\varphi_{3}}\left(\frac{\xi_{3}}{\varphi_{3}}\right)^{-1} p_{2 s}, \quad 1 \leq s \leq k-1
$$

As before, Substituting equations (14) and (16) into (18) with $s=1,2,3, \ldots,(k-1)$ and by recursive manipulation, we get:

$$
\begin{gathered}
p_{3 s}=\frac{1}{\varphi_{3}}\left[\left(\frac{\xi_{3}}{\varphi_{3}}\right)^{s-1} u_{3}-\frac{u_{2} \omega_{3}}{\varphi_{2}} \sum_{1}^{s-1}=1\left(\frac{\xi_{3}}{\varphi_{3}}\right)^{s-\tau_{1}-1}\left(\frac{\xi_{2}}{\varphi_{2}}\right)^{\tau_{1}-1}\right. \\
\left.+\frac{u_{1} \omega_{2} \omega_{3}}{\varphi_{2}} \sum_{\tau_{1}=1}^{s-2} \xi_{1}^{\tau_{1}-1} \sum_{\tau_{1}=1}^{s-1}\left(\frac{\xi_{3}}{\varphi_{3}}\right)^{s-\tau_{2}-1}\left(\frac{\xi_{2}}{\varphi_{2}}\right)^{\tau_{2}-\tau_{1}}\right] p_{0}, 1 \leq s \leq k
\end{gathered}
$$

As well, from the second equation of (3) with $n=3$ and equations (5), (14) and (19), we find: 


$$
p_{41}=\frac{u_{4}}{\varphi_{4}} p_{0}
$$

with $u_{4}=\left(\frac{\xi_{3}}{\varphi_{3}}\right)^{k} u_{3}-\frac{u_{2} \omega_{3}}{\varphi_{2}} \sum_{\tau_{1}=1}^{k}\left(\frac{\xi_{3}}{\varphi_{3}}\right)^{k-\tau_{1}}\left(\frac{\xi_{2}}{\varphi_{2}}\right)^{\tau_{1}-1}$

$$
+\frac{u_{1} \omega_{2} \omega_{3}}{\varphi_{2}} \sum_{\tau_{1}=1}^{k-1} \xi_{1}^{\tau_{1}} 1^{-1} \sum_{\tau_{2}=\tau_{1}}^{k-1}\left(\frac{\xi_{3}}{\varphi_{3}}\right)^{k-\tau_{2}-1}\left(\frac{\xi_{2}}{\varphi_{2}}\right)^{\tau_{2}-\tau_{1}}
$$

Also, from the first equation of (3) with $n=3$ and equations (5), (19) and (20) with $s=1,2,3, \ldots,(k-1)$ and by recursive manipulation, we get:

$$
\begin{aligned}
p_{4 s}= & \frac{1}{\varphi_{4}}\left\{\left(\frac{\xi_{4}}{\varphi_{4}}\right)^{s-1} u_{4} p_{0}-\frac{u_{3} \omega_{4}}{\varphi_{3}} \sum_{\tau_{1}=1}^{s-1}\left(\frac{\xi_{4}}{\varphi_{4}}\right)^{s-\tau_{1}-1}\left(\frac{\xi_{3}}{\varphi_{3}}\right)^{\tau_{1}-1}\right. \\
+ & \frac{u_{2} \omega_{3} \omega_{4}}{\varphi_{2} \varphi_{3}} \sum_{\tau_{1}=1}^{s-2}\left(\frac{\xi_{2}}{\varphi_{2}}\right)^{\tau_{1}-1} \sum_{\tau_{2}=\tau_{1}}^{s-2}\left(\frac{\xi_{4}}{\varphi_{4}}\right)^{s-\tau_{2}-2}\left(\frac{\xi_{3}}{\varphi_{3}}\right)^{\tau_{2}-\tau_{1}} \\
& -\frac{u_{1} \omega_{2} \omega_{3} \omega_{4}}{\varphi_{2} \varphi_{3}} \sum_{\tau_{1}=1}^{s-3} \xi_{1}^{\tau_{1}-1} \sum_{2}^{s-3}=\tau_{1}\left(\frac{\xi_{2}}{\varphi_{2}}\right)^{\tau_{2}-\tau_{1}} \\
& \left.\times \sum_{\tau_{3}=\tau_{2}}^{s-3}\left(\frac{\xi_{4}}{\varphi_{4}}\right)^{s-\tau_{3}-1}\left(\frac{\xi_{3}}{\varphi_{3}}\right)^{\tau_{3}-\tau_{2}-3}\right\} p_{0, \quad 1 \leq s \leq k}
\end{aligned}
$$

From the second equation of (3) with $n=4$ and equations (5), (19) and (22), we find:

$$
p_{51}=\frac{u_{5}}{\varphi_{5}} p_{0}
$$

with $u_{5}=\left(\frac{\xi_{4}}{\varphi_{4}}\right)^{k} u_{4}-\frac{u_{3} \omega_{4}}{\varphi_{3}} \sum_{\tau_{1}=1}^{k}\left(\frac{\xi_{4}}{\varphi_{4}}\right)^{k-\tau_{1}}\left(\frac{\xi_{3}}{\varphi_{3}}\right)^{\tau_{1}-1}$

$$
\begin{gathered}
+\frac{u_{2} \omega_{3} \omega_{4}}{\varphi_{2} \varphi_{3}} \sum_{\tau_{1}=1}^{k-1}\left(\frac{\xi_{2}}{\varphi_{2}}\right)^{\tau_{1}-1} \sum_{\tau_{2}=\tau_{1}}^{s-1}\left(\frac{\xi_{4}}{\varphi_{4}}\right)^{k-\tau_{2}-1}\left(\frac{\xi_{3}}{\varphi_{3}}\right)^{\tau_{2}-\tau_{1}} \\
-\frac{u_{1} \omega_{2} \omega_{3} \omega_{4}}{\varphi_{2} \varphi_{3}} \sum_{\tau_{1}=1}^{k-2} \xi_{1}^{\tau_{1}-1} \sum_{\tau_{2}=\tau_{1}}^{k-2}\left(\frac{\xi_{2}}{\varphi_{2}}\right)^{\tau_{2}-\tau_{1}} \sum_{\tau_{3}=\tau_{2}}^{k-2}\left(\frac{\xi_{4}}{\varphi_{4}}\right)^{k-\tau_{3}-2}\left(\frac{\xi_{3}}{\varphi_{3}}\right)^{\tau_{3}-\tau_{2}}
\end{gathered}
$$

Finally, from the first equation of (3) with $n=5$ and equations (5), (22) and (23) with $s=1,2,3, \ldots,(k-1)$ and by recursive manipulation, we get:

$$
p_{5 s}=\frac{1}{\varphi_{5}}\left\{\left(\frac{\xi_{5}}{\varphi_{5}}\right)^{s-1} u_{5}-\frac{u_{4} \omega_{5}}{\varphi_{4}} \sum_{1}^{s-1}=\left(\frac{\xi_{5}}{\varphi_{5}}\right)^{s-\tau_{1}-1}\left(\frac{\xi_{4}}{\varphi_{4}}\right)^{\tau_{1}-1}\right.
$$




$$
\begin{gathered}
+\frac{u_{3} \omega_{4} \omega_{5}}{\varphi_{3} \varphi_{4}} \sum_{\tau_{1}=1}^{s-2}\left(\frac{\xi_{3}}{\varphi_{3}}\right)^{\tau_{1}-1} \sum_{\tau_{2}=\tau_{1}}^{s-2}\left(\frac{\xi_{5}}{\varphi_{5}}\right)^{s-\tau_{2}-2}\left(\frac{\xi_{4}}{\varphi_{4}}\right)^{\tau_{2}-\tau_{1}} \\
-\frac{u_{1} \omega_{2} \omega_{3} \omega_{4} \omega_{5}}{\varphi_{2} \varphi_{3} \varphi_{4}} \sum_{\tau_{1}=1}^{s-4} \xi_{1}^{\tau_{1}-1} \sum_{\tau_{2}=\tau_{1}}^{s-4}\left(\frac{\xi_{2}}{\varphi_{2}}\right)^{\tau_{2}-\tau_{1}} \sum_{\tau_{3}=\tau_{2}}^{s-4}\left(\frac{\xi_{3}}{\varphi_{3}}\right)^{\tau_{3}-\tau_{2}} \\
\left.\times \sum_{\tau_{3}=\tau_{2}}^{s-4}\left(\frac{\xi_{5}}{\varphi_{5}}\right)^{s-\tau_{4}-4}\left(\frac{\xi_{4}}{\varphi_{4}}\right)^{\tau_{3}-\tau_{2}}\right\} p_{0,} \quad 1 \leq s \leq k
\end{gathered}
$$

Using equations (11), (20), (26), (32) and (38) the following general relation can be derived:

$$
p_{n s}=\mathrm{M}_{n s} p_{0}, \quad n \geq 1, \quad 1 \leq s \leq k
$$

where $\mathbf{M}_{n s}=\frac{1}{\varphi_{n}}\left\{\left(\frac{\xi_{n}}{\varphi_{n}}\right)^{s-1} u_{n}+\sum_{j=0}^{n-2}(-1)^{j+1} u_{n-j-1}\right.$

$$
\begin{gathered}
\left.\times\left[\prod_{i=0}^{j}\left(\frac{\omega_{n-i}}{\varphi_{n-i-1}} \sum_{\tau_{i+1}=\tau_{i}}^{s-j-1}\left(\frac{\xi_{n-i-1}}{\varphi_{n-i-1}}\right)^{\tau_{i+1}-\tau_{i}}\right)\right]\left(\frac{\xi_{n}}{\varphi_{n}}\right)^{s-j-\tau_{j+1}-1}\right\}, \\
\tau_{0}=1, \quad 1 \leq s \leq k, \quad n \geq 1
\end{gathered}
$$

with

$$
u_{n}=\left\{\begin{array}{l}
\omega_{0}, \quad n=1 \\
u_{1}\left(\xi_{1}^{k}-1\right), \quad n=2 \\
\left(\frac{\xi_{n-1}}{\varphi_{n-1}}\right)^{k} u_{n-1}+\sum_{j=0}^{n-3}(-1)^{j+1} u_{n-j-2} \\
\times\left[\prod_{i=0}^{j}\left(\frac{\omega_{n-i-1}}{\varphi_{n-i-2}} \sum_{\tau_{i+1}=\tau_{i}}^{k-j}\left(\frac{\xi_{n-i-2}}{\varphi_{n-i-2}}\right)^{\tau_{i+1}-\tau_{i}}\right)\right]\left(\frac{\xi_{n-1}}{\varphi_{n-1}}\right)^{k-j-\tau_{j+1}}, n \geq 3
\end{array}\right.
$$

From equation (26) and using the normalizing condition $p_{0}+\sum_{n=1}^{\infty} p_{n s}=1$ one obtains:

$$
p_{0}^{-1}=1+\sum_{n=1}^{\infty} p_{n s}, 1 \leq s \leq k
$$

And, from the above relationship, the expected number of units in the system and in the queue is:

$$
\begin{gathered}
L=\sum_{n=1}^{\infty} n \mathbf{M}_{n s} p_{0}, \\
L_{q}=L+p_{0}-1
\end{gathered}
$$

\section{Special Cases}

Some queuing systems can be obtained as special cases of this system:

Case (1): Let $\alpha=0$ and $q=1$, this is the non-truncated single-channel Erlangian queue: M/Ek/1 with balking studied by Kotb [2].

Case (2): Let $p=1$ and $q=1$, this is the non-truncated single-channel Erlangian queue: $\mathrm{M} / \mathrm{Ek} / 1$ with balking and reneging studied by Shawky and paoumy [3], [7] respectively.

Case (3): Let $\alpha=0, \beta=1$ and $q=1$, this is the nontruncated single-channel Erlangian queue: M/Ek/1 without any concepts studied by white [1].

\section{An Illustrative Example}

Assume the parameters $n=2$ units, $k=4$ phase of service. The results of $p_{n s}, p_{0}, L, L_{q}, W$ and $W_{q}$ for different values of $\beta, \lambda, \mu, q, \alpha$ and $p$ are shown in the following table 1 : 
Table 1. The results of $p_{n s}, p_{0}, L, L_{q}, W$ and $W_{q}$

\begin{tabular}{ccccccccccccc}
\hline $\boldsymbol{\beta}$ & $\boldsymbol{\lambda}$ & $\boldsymbol{\mu}$ & $\boldsymbol{q}$ & $\boldsymbol{\alpha}$ & $\boldsymbol{p}$ & $\boldsymbol{p}_{\boldsymbol{0}}$ & $\boldsymbol{p}_{\mathbf{2 1}}$ & $\boldsymbol{p}_{\mathbf{2 2}}$ & $\boldsymbol{p}_{\mathbf{2 3}}$ & $\boldsymbol{p}_{\mathbf{2 4}}$ & $\boldsymbol{L}$ & $\boldsymbol{L}_{\boldsymbol{q}}$ \\
\hline 0.1 & 5 & 8 & 0.9 & 1 & 0.7 & 0.97 & 0.0117 & 0.009 & 0.006 & 0.004 & 0.061 & 0.031 \\
0.3 & 6 & 9 & 0.8 & 2 & 0.6 & 0.86 & 0.0474 & 0.039 & 0.030 & 0.020 & 0.274 & 0.137 \\
0.5 & 7 & 10 & 0.6 & 3 & 0.4 & 0.59 & 0.1185 & 0.111 & 0.099 & 0.082 & 0.821 & 0.410 \\
0.7 & 8 & 11 & 0.4 & 4 & 0.2 & 0.19 & 0.1672 & 0.192 & 0.215 & 0.235 & 1.619 & 0.809 \\
0.9 & 9 & 12 & 0.2 & 5 & 0.1 & 0.001 & 0.0923 & 0.159 & 0.273 & 0.466 & 1.980 & 0.990 \\
\hline
\end{tabular}

Solution of the model may be determined more readily by plotting $p_{0}, p_{n s}, L$ and $L_{q}$ are drawn against $\beta, \lambda, \mu, q, \alpha$ and $p$ as given in Figures 1, 2, 3, 4, 5 and 6 respectively.

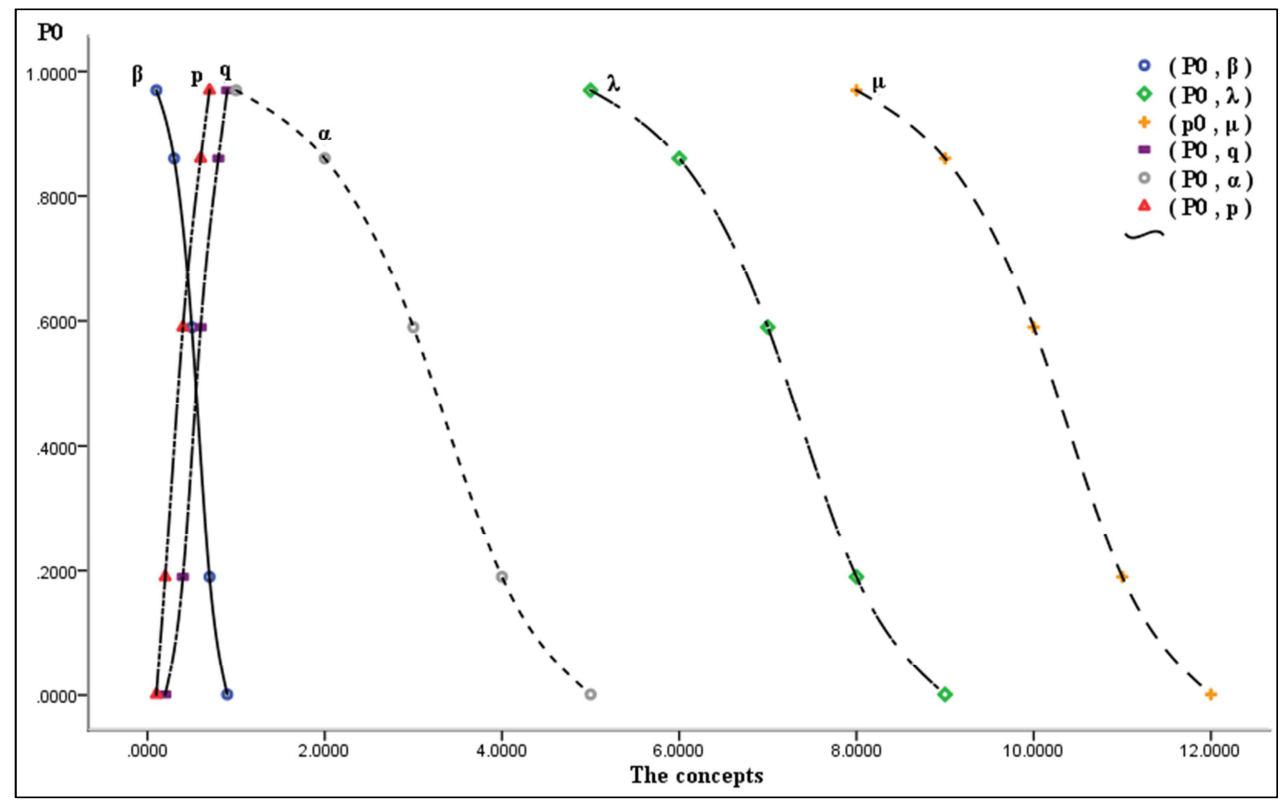

Figure 1. The relation between $p_{0} \&(\beta, \lambda, \mu, q, \alpha$ and $p)$.

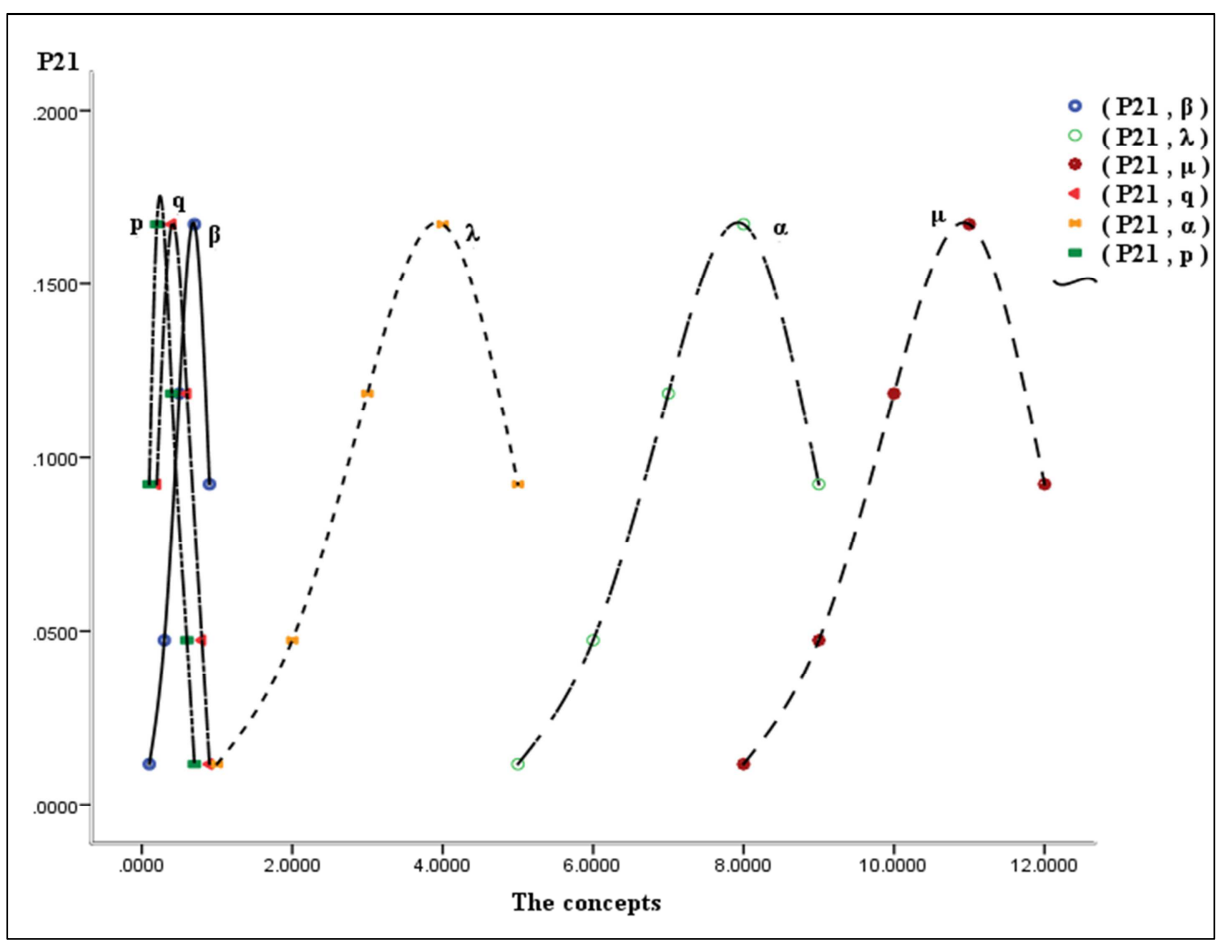

Figure 2. The relation between $p_{21} \&(\beta, \lambda, \mu, q, \alpha$ and $p)$. 


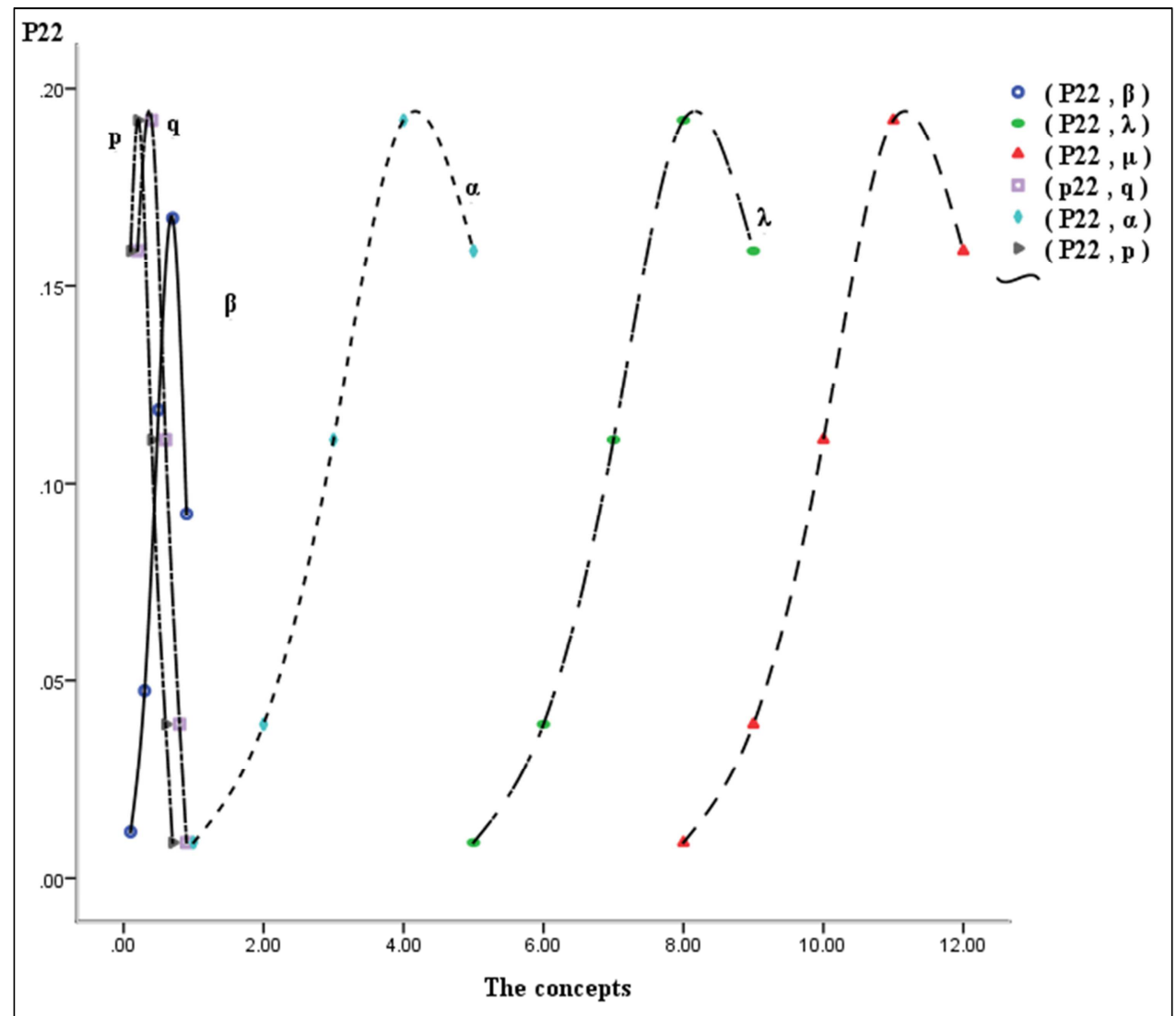

Figure 3. The relation between $p_{22} \&(\beta, \lambda, \mu, q, \alpha$ and $p)$.

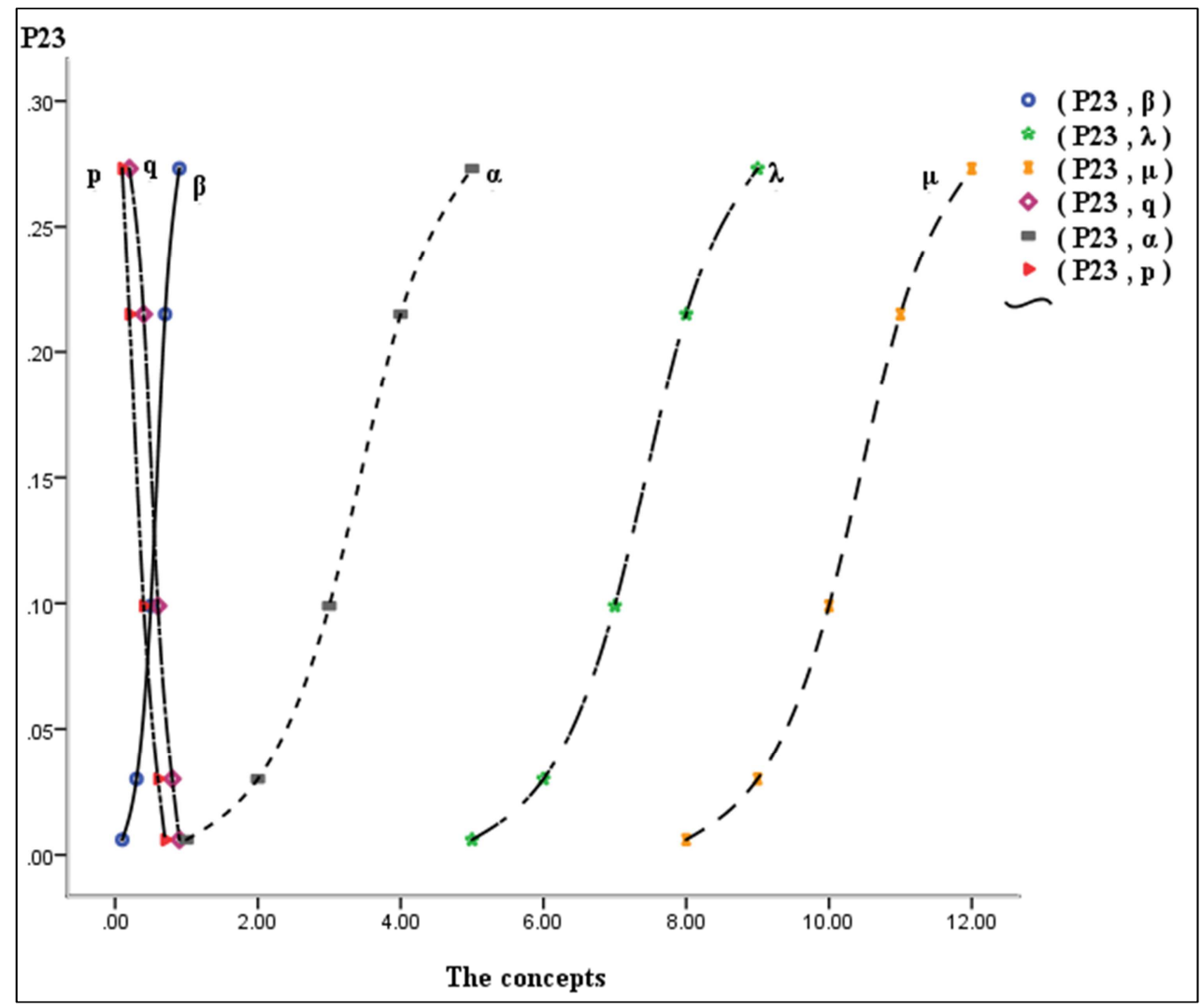

Figure 4. The relation between $p_{23} \&(\beta, \lambda, \mu, q, \alpha$ and $p)$. 


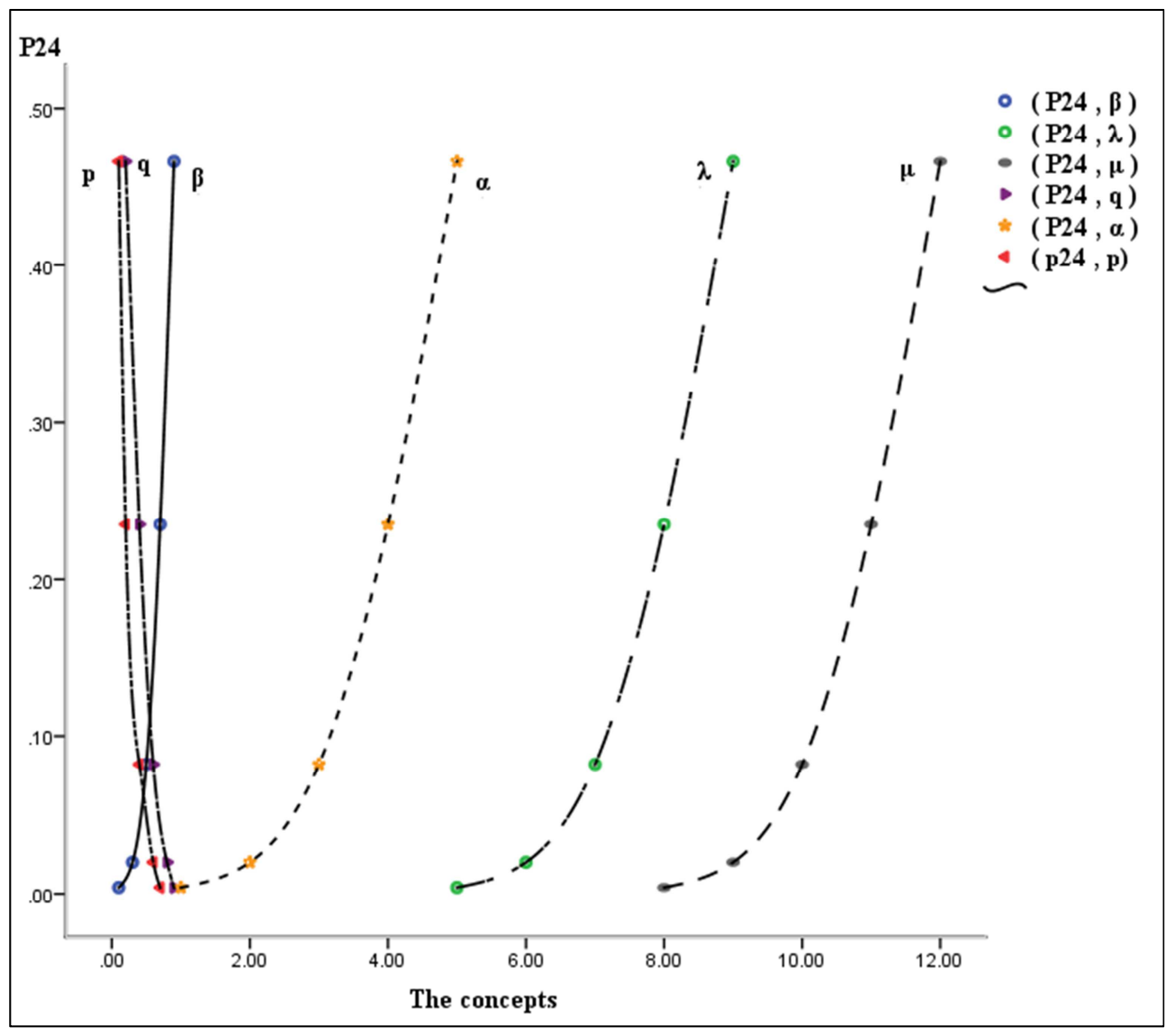

Figure 5. The relation between $p_{24} \&(\beta, \lambda, \mu, q, \alpha$ and $p)$.

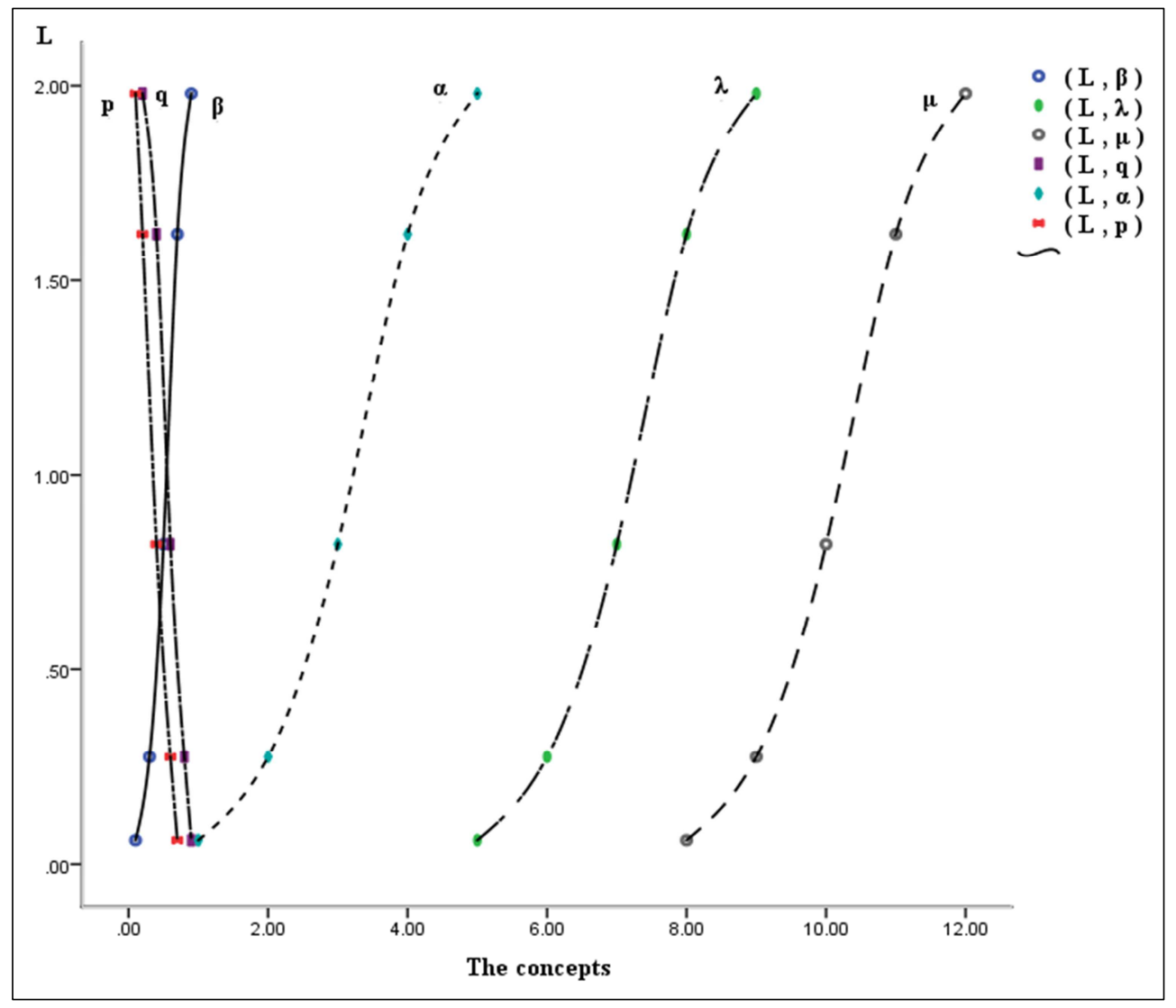

Figure 6. The relation between $L \&(\beta, \lambda, \mu, q, \alpha$ and $p)$. 


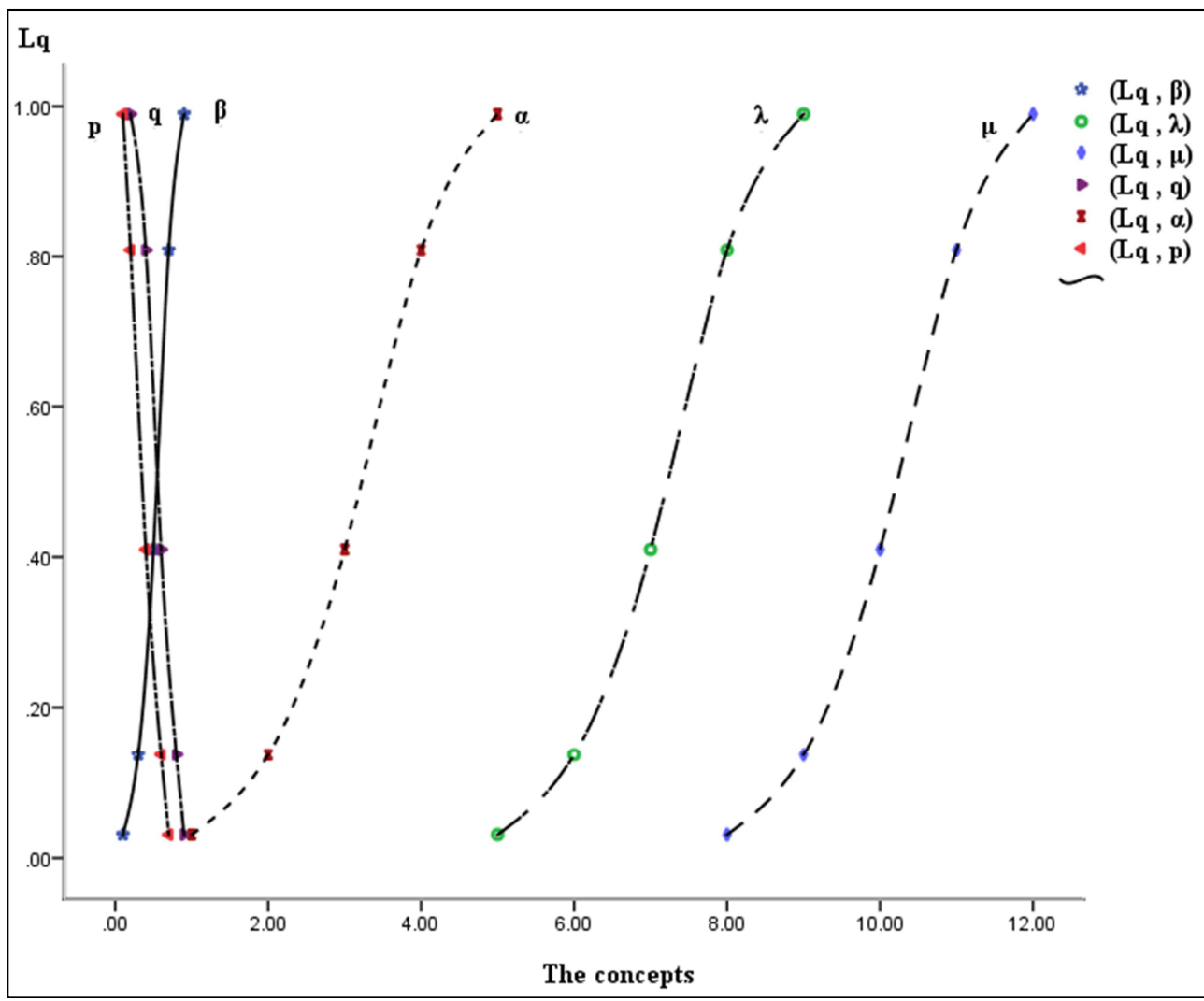

Figure 7. The relation between $L_{q} \&(\beta, \lambda, \mu, q, \alpha$ and $p)$.

As we can see in graph1, shows that the increased the both of (arrival rate, service rate, Balking and reneging) and decrease the both of (the feedback strategy, and retention of reneged customers) offset it decrease the probability that there are no customers in the system. It is seen in graphs 2, 3, 4 and 5 respectively, shows that the increased the both of (arrival rate, service rate, Balking and reneging) and decrease the both of (the feedback strategy, and retention of reneged customers) offset it increase in the probability that there are $n$ of customers in the system. Also in graph6, shows that the increased the both of (arrival rate, service rate, Balking and reneging) and decrease the both of (the feedback strategy, and retention of reneged customers) offset it increase in the expected number of customers in the system. And in graph7, shows that the increased the both of (arrival rate, service rate, Balking and reneging) and decrease the both of (the feedback strategy, and retention of reneged customers) offset it increase in the expected number of customers in the queue.

\section{Conclusion}

This paper has derive the analytical solution in steady-state for $\mathrm{M} / \mathrm{E}_{\mathrm{k}} / 1$ with adding the feedback, balking and retention of reneged customers using the iterative method were devised to determine the probabilities that there are $n$ customers in the system, the customer in service being in phase $s$ and the probability that no customers are in the service department, the expected number of customers in the system and the expected number of customers in the queue. Finally, the numerical example was confirmed to confirm the model. The results, increasing (the probabilities that there are $n$ customers in the system and the customer in service being in phase $s$, the number clients expected in the system) with increasing utilization factor, balking and retention of reneged customers. Also, the probability that there were no units in the system decreased with increasing utilization factor, balking and retention of reneged customers. Possible future extention of this work was include quality control process.

\section{References}

[1] J. A. White, J. W. Schmidt and G. K. Bennett, Analysis of queueing system, Academic press, New York, (1975).

[2] K. A. M Kotb, state-dependent queues, Ph.D. Thesis, faculty of science, Tanta university, 1994.

[3] A. I. Shawky, The service Erlangian machine interference model: $\mathrm{M} / \mathrm{Er} / 1 / \mathrm{k} / \mathrm{N}$ with balking and reneging, Journal applied mathematics \& computing, 18 (2005), 431-439.

[4] Madhu Jain and Praveen Kumar, $M / E_{k} / 1$ queueing system with working vacation, queuing systems, 4 (2007), 455 - 470.

[5] D. Groos and C. M. Harris, Fundamentals of queueing theory, New York, John wiley and sons, 4th edition, (2008).

[6] S. S. Mishra and Dinesh Kumar Yadav, Cost and profit analysis of $\mathrm{M} / \mathrm{Ek} / 1$ queueing system with removable service station, Applied mathematical sciences, 2 (2008), 2777 - 2784. 
[7] M. S. El-Paoumy and M. M. Ismail, On a truncated Erlang queuing system with bulk arrivals, balking and reneging, Applied mathematical sciences, 3 (2009), 1103-1113.

[8] Namh. A. Abid and Azmi. K. Al - Madi, On the queuing system $\mathrm{M} / \mathrm{Er} / 1 / \mathrm{N}$, Baghdad science journal, 9 (2012), 367371 .

[9] P. Jayachitra and A. James Albert, Optimal management policy for heterogeneous arrival $\mathrm{M} / \mathrm{E}_{\mathrm{K}} / 1$ queueing system with server breakdowns and multiple vacations, Advances in theoretical and applied mathematics, 1 (2014), 87-95.

[10] P. Jayachitra and A. James Albert, Performance analysis of an n-policy $\mathrm{M} / \mathrm{Ek} / 1$ queueing system with server start up, unreliable server and balking, International journal of mathematical archive, 6 (2015), 159-169.
[11] P. Jayachitra and A. James Albert, Analysis of an n-policy $\mathrm{M} / \mathrm{E}_{\mathrm{k}} / 1$ queueing system with unreliable server, multiple vacations and balking, International journal of mathematics trends and technology, 21 (2015), 2231-5373.

[12] K. A. M. Kotb and Moamer Akhdar, feedback of M/M/1 queue with catastrophe, repair and retention of reneged customers via transient behavior approach, Sylwan, 161 (2017), 357-371.

[13] K. Jeganathan, M. Abdul Reiyas, S. Padmasekaran and K. Lakshmanan, An $\mathrm{M} / \mathrm{E}_{\mathrm{K}} / 1 / \mathrm{N}$ queueing-inventory system with two service rates based on queue lengths, International Journal applied mathematics and computing, 1 (2017), 360-388. 